\title{
Low frequency of imprinting defects in ICSI children born small for gestational age
}

\author{
Deniz Kanber ${ }^{1}$, Karin Buiting ${ }^{1}$, Michael Zeschnigk ${ }^{1}$, Michael Ludwig ${ }^{2}$ and \\ Bernhard Horsthemke*,1
}

\author{
${ }^{1}$ Institut für Humangenetik, Universitätsklinikum Essen, Essen, Germany; ${ }^{2}$ Endokrinologikum Hamburg, Hamburg, \\ Germany
}

Although there is an increased frequency of low birth weight after assisted reproduction, the mechanisms underlying this association are unclear. We have proposed that some of the children conceived by intracytoplasmic sperm injection (ICSI) with low birth weight might have an epimutation (faulty methylation pattern) in one of the imprinted genes involved in fetal growth control, eg, KCNQ10T1, PEG1, PEG3, GTL2, IGF2/H19 and PLAGL1. Using bisulfite DNA sequencing and sequence-based quantitative methylation analysis (SeQMA), we determined the methylation pattern of these genes in buccal smears from 19 ICSI children born small for gestational age (SGA, birth weight $<3$ rd percentile) and from 29 termborn normal weight children after spontaneous conception. We detected clear hypermethylation of KCNQ1OT1 and borderline hypermethylation of PEG1 in one and the same ICSI child. The other children and the parents of the affected child have normal methylation patterns. Imprinting defects appear to be a rare finding in ICSI children born SGA. Methylation of the paternal KCNQ1OT1 and PEG1 alleles may be a previously unrecognized cause of SGA. The epimutations found in the SGA child, whose father had oligozoospermia, probably result from an imprint erasure defect in the paternal germ line and therefore appear to be linked to the fertility problem of the father and not to in vitro fertilization/ICSI.

European Journal of Human Genetics (2009) 17, 22 -29; doi:10.1038/ejhg.2008.177; published online 22 October 2008

Keywords: ICSI; hypermethylation; KCNQ1OT1; PEG1

\section{Introduction}

Children born after in vitro fertilization/intracytoplasmic sperm injection (ICSI) have an increased risk of premature birth, low birth weight, sex chromosome abnormalities, malformations and possibly imprinting disorders. ${ }^{1}$ Epigenetic defects (faulty gene expression states) appear to contribute to some of these problems. ${ }^{2}$ At present, it is unclear whether the defects are linked to the subfertility of the parents or the technique.

\footnotetext{
*Correspondence: Professor B Horsthemke, Institut für Humangenetik, Universitätsklinkum Essen, Hufelandstrasse 55, 45122 Essen, Germany. Tel: + 49201723 4560; Fax: + 49201723 5900;

E-mail: bernhard.horsthemke@uni-due.de

Received 12 June 2008; revised 19 August 2008; accepted 3 September 2008; published online 22 October 2008
}

In humans and other placental mammals, approximately 100 genes are subject to genomic imprinting. Imprinted genes are expressed from one of the parental alleles only and appear to control resource acquisition of the embryo and fetus. ${ }^{3,4}$ They operate in the placenta, the fetus or both. Paternally expressed genes such as PLAGL1, PEG1 (paternally expressed gene 1), IGF2, KCNQ1OT1 and PEG3 enhance fetal growth, whereas maternally expressed genes such as GTL2 and CDKN1C appear to restrict fetal growth. Rare overgrowth syndromes in humans and animals are caused by the loss of maternal gene expression (CDKN $1 C^{5}$ in Beckwith-Wiedemann syndrome and IGF2R in animals with large offspring syndrome ${ }^{6}$ ) or gain of maternal gene expression (IGF2 in Beckwith-Wiedemann syndrome ${ }^{7}$ ). Reduced paternal IGF2 expression is found in $\sim 50 \%$ of patients with Silver-Russell syndrome, which is characterized by pre- and postnatal growth retardation. ${ }^{8,9}$ On the 
basis of the findings in these rare syndromes, it is possible that the dysregulation of imprinted genes may contribute to low birth weight in children.

DNA methylation at differentially methylated regions (DMRs) is one of the regulatory mechanisms controlling allele-specific expression of imprinted genes. Parental methylation imprints are erased in primordial germ cells, differentially established during spermatogenesis and oogenesis, and maintained during postzygotic development. Errors in imprint erasure, imprint establishment and imprint maintenance lead to aberrant imprints (imprinting defects $\left.{ }^{10}\right)$. As these defects do not affect the DNA sequence, they represent primary epimutations. We have investigated whether ICSI children born small for gestational age (SGA) have epimutations at one or more imprinted loci controlling fetal growth.

\section{Materials and methods}

\section{Patients and controls}

Children who were born SGA (birth weight $<3$ rd percentile) were recruited from a prospective study on ICSI. ${ }^{11}$ Among 2055 singletons born in the study group, we identified 60 SGA children. In 38 cases, the parents had previously given consent to be contacted again. In total, 19 parents agreed to send buccal smears from their child and themselves. At this time, the children were between 4 and 7 years old. Week of gestation, birth weight and birth size of the SGA children are listed in Table 1. For controls, we collected samples from 29 age-matched spontaneously conceived children with a normal birth weight.

\section{DNA preparation}

DNA was extracted and purified from buccal cells using the EZ1 DNA Tissue Kit (Qiagen, Hilden, Germany) following the manufacturer's instructions.

\section{Bisulfite treatment of genomic DNA}

Bisulfite treatment of genomic DNA was modified from established protocols. Genomic DNA (500 ng in $50 \mu \mathrm{l}$ ) was denatured by adding $5.5 \mu \mathrm{l}$ freshly prepared $3 \mathrm{M} \mathrm{NaOH}$ and incubating the solution at $37^{\circ} \mathrm{C}$ for $15 \mathrm{~min}$. For complete denaturation, the samples were incubated at $95^{\circ} \mathrm{C}$ for $2 \mathrm{~min}$ and immediately cooled on ice. The bisulfite solution was prepared by dissolving $8.5 \mathrm{~g}$ of sodium bisulfite in $15 \mathrm{ml}$ degassed water, adding $900 \mu \mathrm{l}$ of a $50 \mathrm{~mm}$ hydroquinone solution, and adjusting the $\mathrm{pH}$ to 5.1 with $1000 \mu \mathrm{l}$ of $10 \mathrm{M}$
$\mathrm{NaOH}$. The bisulfite solution $(500 \mu \mathrm{l})$ was added to the denatured DNA, mixed and incubated at $50^{\circ} \mathrm{C}$ for $16 \mathrm{~h}$ in the dark. The DNA was recovered by using the Wizard DNA Clean-Up System (Promega) followed by elution in $50 \mu \mathrm{l}$ water. Subsequently, $5.5 \mu \mathrm{l}$ of $3 \mathrm{M} \mathrm{NaOH}$ was added, and the samples were incubated for $15 \mathrm{~min}$ at $37^{\circ} \mathrm{C}$. The solution was then neutralized by adding $55 \mu \mathrm{l}$ of $6 \mathrm{M} \mathrm{NH} 4 \mathrm{OAc} \mathrm{pH}$ 7.0. The DNA was ethanol precipitated, washed in $70 \%$ ethanol, dried and resuspended in $8 \mu \mathrm{l}$ water.

\section{Sequence-based quantitative methylation analysis}

Sequence-based quantitative methylation analysis (SeQMA) allows determining the degree of methylation of all CpGs in a given sequence. ${ }^{12}$

First, genomic DNA is treated with sodium bisulfite, which converts unmethylated cytosine residues to uracil, whereas methylated cytosine residues remain unchanged. This results in specific sequence changes. PCR is performed on the bisulfite-treated DNA and the products are subjected to the Taq cycle sequencing procedure with fluorescencelabeled dideoxynucleotides. The sequencing products are subjected to capillary gel electrophoresis and analyzed with the GeneScan software (ABI). By comparing thymine peak areas at $\mathrm{CpG}$ sites with genomic thymine peak areas at control sites (non-CpG sites), the degree of methylation can be determined. Thymine residues that are present in the original sequence have an invariable peak height and area, whereas thymine peak heights and areas at CpG sites are variable after bisulfite treatment depending on the methylation status (Figure 2).

An aliquot of bisulfite-treated genomic DNA $(1 \mu \mathrm{l})$ was used for each PCR in a total volume of $25 \mu \mathrm{l}$. For improved sequencing results, we used primers with a tag (forward 5'-CTTGCTTCCTGGCACGAG-3' and reverse 5'-CAGGAAA CAGCTATGAC- $3^{\prime}$ ), which contain cytosine and guanine residues. PCR conditions were as follows: $95^{\circ} \mathrm{C}$ for $10 \mathrm{~min}$, 35 cycles of $95^{\circ} \mathrm{C}$ for $20 \mathrm{sec}$, annealing for $20 \mathrm{~s}$ (annealing temperatures are given in Table 2 ), $72^{\circ} \mathrm{C}$ for $30 \mathrm{~s}$; finally $7 \mathrm{~min}$ at $72^{\circ} \mathrm{C}$. The PCR products were gel purified by Wizard SV ${ }^{\circledR}$ Gel and PCR Clean-Up System (Promega). The sequence reaction was performed with Big Dye Terminators (BigDye $^{\circledR}$ Terminator v1.1 Cycle Sequencing Kit; Applied Biosystems) and the forward tag primer. Cycle sequencing conditions were as follows: $96^{\circ} \mathrm{C}$ for $1 \mathrm{~min}, 25$ cycles of $96^{\circ} \mathrm{C}$ for $10 \mathrm{~s}, 56^{\circ} \mathrm{C}$ for 5 and $60^{\circ} \mathrm{C}$ for $4 \mathrm{~min}$. After adding $1 \mu \mathrm{l}$ of GeneScan-LIZ 500 size standard, the sequencing products were subjected to fragment analysis on an $\mathrm{ABI}$

Table 1 Week of gestation, birth weight and birth size of the 19 ICSI children

\begin{tabular}{|c|c|c|c|c|c|c|c|c|c|c|c|c|c|c|c|c|c|c|c|}
\hline $\mathrm{amp}$ & 1 & 2 & 3 & 4 & 11 & 12 & 13 & 14 & 21 & 22 & 23 & 24 & 31 & 32 & 33 & 34 & 41 & 42 & \\
\hline ation & 38 & 40 & 39 & 36 & 37 & 38 & 33 & 38 & na & 38 & 38 & 40 & 36 & 25 & 39 & 36 & 37 & 35 & \\
\hline & 2120 & 2240 & 2400 & 2070 & 2200 & 2250 & 1400 & 200 & 2270 & 2490 & 2360 & 2450 & 1990 & 510 & 2440 & 1635 & 810 & 165 & 217 \\
\hline$e(\mathrm{~cm}$ & 45 & 45 & 46 & 44 & 45 & 46 & 40.5 & 48 & na & 46 & 47 & 48 & 43 & 30 & 49 & 44.5 & 43 & 40 & 4 \\
\hline
\end{tabular}

na, not available. 
Table 2 Investigated loci and primer sequences used for bisulfite PCR

\begin{tabular}{|c|c|c|c|c|c|c|}
\hline Gene & Primer & Primer sequence $\left(5^{\prime}-3^{\prime}\right)$ & $\begin{array}{c}\text { Annealing } \\
\text { temperature }\left({ }^{\circ} \mathrm{C}\right)\end{array}$ & $\begin{array}{l}\text { Product } \\
\text { size (bp) }\end{array}$ & $\begin{array}{l}\text { Number } \\
\text { of CpGs }\end{array}$ & $\begin{array}{l}\text { Accession } \\
\text { number }\end{array}$ \\
\hline KCNQ10T1 & $\begin{array}{l}\text { LIT1-Not1-Ftag } \\
\text { LIT1-Not1-RM13 }\end{array}$ & $\begin{array}{l}\text { CTTGCTTCCTGGCACGAGTTTATAGGTTT } \\
\text { TTATATYGAGGGTTTATAGTAG } \\
\text { CAGGAAACAGCTATGACAAATAAACY } \\
\text { RAAAACACRAACCAATTCTCTAC }\end{array}$ & 57 & 156 & 4 & U90095 \\
\hline PEG 1 & $\begin{array}{l}\text { PEG1-Ftag } \\
\text { PEG1-RM13 }\end{array}$ & $\begin{array}{l}\text { CTTGCTTCCTGGCACGAGTYGTTGTTGG } \\
\text { TTAGTITTGTAYGGTT } \\
\text { CAGGAAACAGCTATGACCCAACC } \\
\text { ACACССССTCRTTCCCAC }\end{array}$ & 58 & 184 & 10 & AC144863 \\
\hline PEG3 & $\begin{array}{l}\text { PEG3-Ftag } \\
\text { PEG3-RM13 }\end{array}$ & $\begin{array}{l}\text { CTTGCTTCCTGGCACGAGTTATTAGT } \\
\text { TTAGGGTGGATATITI } \\
\text { CAGGAAACAGCTATGACACTAATTAACTA } \\
\text { ACACAAAAACCCC }\end{array}$ & 56 & 177 & 6 & AC006115 \\
\hline PLAGL1 & $\begin{array}{l}\text { ZAC1-P1-inFtag } \\
\text { ZAC1-P1-RM13 }\end{array}$ & $\begin{array}{l}\text { CTTGCTTCСTGGCAC- } \\
\text { GAGGGGGTTTTITTTGTTAYGTG } \\
\text { CAGGAAACAGCTATGACCCCAACCRTAT } \\
\text { CTAAATCAAAACT }\end{array}$ & 59 & 244 & 8 & AL109755 \\
\hline GTL2 & $\begin{array}{l}\text { GLT2-3.2-Ftag } \\
\text { GTL2-3.2-RM13 }\end{array}$ & $\begin{array}{l}\text { CTTGCTTCСTGGCACGAGAAGAGGGA } \\
\text { ATAGTTTTGAGATTTT } \\
\text { CAGGAAACAGCTATGACTAACСССTCA } \\
\text { CTAACСTTATCACA }\end{array}$ & 59 & 247 & 8 & AL117190 \\
\hline$I G F 2 / H 19$ & $\begin{array}{l}\text { H19-in-Ftag } \\
\text { H19-CTCF-RM13 }\end{array}$ & $\begin{array}{l}\text { CTTGCTTCCTGGCACGAGGGTAY } \\
\text { GGAATTGGTTGTAGTTGTGG } \\
\text { CAGGAAACAGCTATGACATATCCTATTC } \\
\text { CCAAATAACCCC }\end{array}$ & 56 & 204 & 8 & AF087017 \\
\hline
\end{tabular}

$\mathrm{Y}=\mathrm{C}$ or $\mathrm{T} ; \mathrm{R}=\mathrm{G}$ or $\mathrm{A}$; The forward primer for the PEG1 locus was taken from Sato $e$ a $\mathrm{l}^{13}$ and the reverse primer for the $Z A C 1$ locus was taken from Valleley et $a l^{14}$ and both primers were provided with a tag.

3100 Genetic Analyzer using the GeneScan software (Applied Biosystems). Analyzed loci and primer sequences are listed in Table 2. Primers were designed with the help of MethPrimer (http://www.urogene.org/methprimer/) and all of them are within the core region of the corresponding DMR.

Raw data of each CpG peak area (a uracil/thymine target residue generated by bisulfite treatment from a CpG dinucleotide) were exported from the GeneScan software. The lack of cytosine residues outside CpG islands indicates that there was complete conversion of unmethylated cytosines to thymines. The relative peak area (RPA) for each CpG was determined by calculating the ratio of each single CpG peak area to the sum of the nearest control peak areas in the sample (peak area $\mathrm{CpG} / \Sigma$ control peak areas $=\mathrm{RPA}$ ). Control peaks were chosen from thymine residues in the original sequence, which are in close vicinity to the respective CpG. To define a normal 'expected value', we averaged data from five standard DNA samples by calculating the mean RPA for each CpG peak (corresponding to each probe or locus). These samples are from healthy individuals who have normal methylation levels. We compared each RPA to the mean RPA to obtain a percentage value denoted RPA ratio (RPA/mean $\mathrm{RPA}=\mathrm{RPA}$ ratio). The RPA ratios correspond to $50 \%$ of methylation (RPA ratio $\times 50 \%$ ). For assessment of methylation status in target samples, RPAs and RPA ratios were calculated in the same way (RPAs were compared with the expected RPAs). RPA ratios were averaged to calculate RPA ratio $N$ for each target sample. The obtained quantitative values ( $N$ values) show the degree of non-methylation and thus the degree of methylation. As suggested by Dikow et $a l^{12} N$ values $>0.6$ indicate hypomethylation, whereas values $<0.4$ indicate hypermethylation. Values between 0.4 and 0.6 indicate a normal methylation.

The degree of methylation in the standard DNA samples at the different loci analyzed was set to $50 \%$. Thus, in comparison to the ICSI samples, we get relative values for methylation status and can detect methylation abnormalities.

\section{Combined bisulfite restriction analysis}

To confirm the SeQMA results, combined bisulfite restriction analysis (COBRA) was performed. PCR products for KCNQ1OT1 and PEG1 (see above) were digested with BstUI, which only cleaves the recognition site, if the original DNA was methylated. Gel-purified PCR products (150 ng) were digested with the enzyme and electrophoresed on a $3 \%$ agarose gel.

\section{Genomic sequence analysis}

We designed primers for KCNQ1OT1 and PEG1 for unmodified genomic DNA, so that the PCR products span the regions analyzed by SeQMA. For each PCR, 140 ng genomic DNA was used in a total volume of $25 \mu \mathrm{l}$. PCR primers LITnDNA5 forward (GAGACCTTGCCCGGGTTC) 
and LITnDNA4 reverse (ACTGGCTGGGTGTG-AGGT) were used to amplify a 304 bp KCNQ1OT1 region. PCR conditions were as follows: $95^{\circ} \mathrm{C}$ for $2 \mathrm{~min}, 35$ cycles of $95^{\circ} \mathrm{C}$ for $30 \mathrm{~s}, 61^{\circ} \mathrm{C}$ for $30 \mathrm{~s}, 72^{\circ} \mathrm{C}$ for $1 \mathrm{~min}$; finally $5 \mathrm{~min}$ at $72^{\circ} \mathrm{C}$. The PCR products were purified by Microcon (Millipore). The sequence reaction was performed with Big Dye Terminators (BigDye Terminator v1.1 Cycle Sequencing Kit; Applied Biosystems) using the forward and reverse primers, respectively. Cycle sequencing conditions were as follows: $96^{\circ} \mathrm{C}$ for $1 \mathrm{~min}, 25$ cycles of $96^{\circ} \mathrm{C}$ for $10 \mathrm{~s}, 60^{\circ} \mathrm{C}$ for $5 \mathrm{~s}$ and $60^{\circ} \mathrm{C}$ for $4 \mathrm{~min}$. For PEG1, PCR primers PEG1: forward (CCGGAGTGGCTGTAGCTG) and PEG1: reverse (CGCCTGTCGGTAGAGTTTTC) were used to amplify a 306-bp region. PCR and cycle sequencing conditions were the same as for KCNQ1OT1.

\section{Results}

Using a quantitative methylation assay, we studied six DMRs associated with imprinted loci in 19 ICSI/SGA (cases) and 29 age-matched control children. The surveyed regions contain 4 CpGs (KCNQ1OT1), 6 CpGs (PEG3), 8 CpGs (IGF2/H19, PLAGL1 and GTL2) and 10 CpGs (PEG1), respectively. We designated a case as abnormally methylated, if the value was outside the $40-60 \%$ range and not observed in any of the 29 control children. By these criteria, only one ICSI/SGA child (no. 33) had abnormal methylation levels (hypermethylation of KCNQ1OT1 and PEG1; Figure 1). A few cases had KCNQ1OT1 methylation levels slightly less than $40 \%$, but so had some control children. Two control children, but no cases had GTL2 methylation levels slightly higher than $60 \%$.

Child no. 33 had 74\% methylation of KCNQ1OT1 and $63 \%$ methylation of PEG1 (Figure 1). As judged by singlesite methylation analysis (Figure 2), all CpGs tested showed the same degree of hypermethylation. Similar findings (72 and $60 \%$, respectively) were made in another independent SeQMA experiment (not shown) and confirmed by an independent method (COBRA; Figure 3). The parents of child no. 33 had normal methylation levels (P1 and P2 in Figure 1).

As we were aware of a single nucleotide polymorphism (SNP) in the primer-binding site of the primer LIT1-Not1RM13 (rs11023840), which might bias the PCR and thus confound the SeQMA and COBRA analyses, we had included a wobble in the sequence (see Materials and methods). The fact that child no. 33 and her mother are heterozygous for this SNP (Supplementary Figure 1), yet only the child shows abnormal KCNQ1OT1 methylation levels, argues against a confounding role of this SNP in our analysis. To search for other variants in the KCNQ1OT1 and PEG1 primer-binding sites, we sequenced the two loci in unmodified genomic DNA. As shown in Supplementary Figure 1, child no. 33 is homozygous for the reference sequence, apart from the rs11023840 SNP in the LIT1Not1-RM13 primer.

Child no. 33 was conceived by ICSI because of male factor infertility with a low sperm count (4 million sperms $/ \mathrm{ml}$ ). She was born after 39 weeks of gestation and had a birth weight of $2440 \mathrm{~g}$ and a length of $49 \mathrm{~cm}$. She showed catch-up growth after birth and has developed normally (Supplementary Figure 2). She has no phenotypic abnormalities.

\section{Discussion}

The present study was designed to determine whether imprinting defects contribute to SGA in ICSI children. The patients were recruited from a prospective study on the outcome of ICSI. ${ }^{11}$ Among 19 ICSI/SGA children, we identified only one child with putative imprinting defects of KCNQ1OT1 and PEG1. None of the children had SilverRussell syndrome, which often results from hypomethylation of $I G F 2 / H 19 .{ }^{8}$ Our results show that imprinting defects are not frequent in ICSI/SGA children, at least not at the six loci investigated in this study. However, our study is limited by the fact that we could investigate only one tissue (buccal smear) at only one time point. Most importantly, we did not have newborn and placental material. Owing to the fact that imprinting defects are often mosaic (see discussion below), the frequency of imprinting defects might actually be higher than observed in our study.

By SeQMA, one child had 72-74\% methylation of KCNQ1OT1 and 60-63\% methylation of PEG1. The parents were normal at these loci. The latter finding and our genomic sequence analysis exclude the possibility that our analysis was confounded by an SNP, and indicate that the child has a de novo hypermethylation. Although the results were confirmed by an independent method (COBRA), the findings in PEG1 are borderline. We note, however, that child no. 33 has the highest degree of PEG1 methylation among all 48 children. The results between two SeQMA experiments are reassuringly similar, showing that there is little inter-experiment variation, but there appears to be a certain degree of inter-individual variation in methylation, which makes the detection of mosaic imprinting defects difficult.

Do our findings make sense? Hypermethylation of KCNQ1OT1 and PEG1 means that the paternal allele is methylated, which is normally unmethylated. PEG1 is located in 7q32, encodes a member of the alpha/beta hydroxylase fold family and is paternally expressed in human fetal tissues. The promoter region is methylated on the maternal chromosome and unmethylated on the paternal chromosome. ${ }^{15}$ Maternal uniparental disomy 7 (complete methylation at this locus) is associated with preand postnatal growth retardation, but the role of PEG1 in this condition is unknown. Lefebvre et $a l^{16}$ showed that 
Degree of methylation at $K C N Q 1 O T 1$

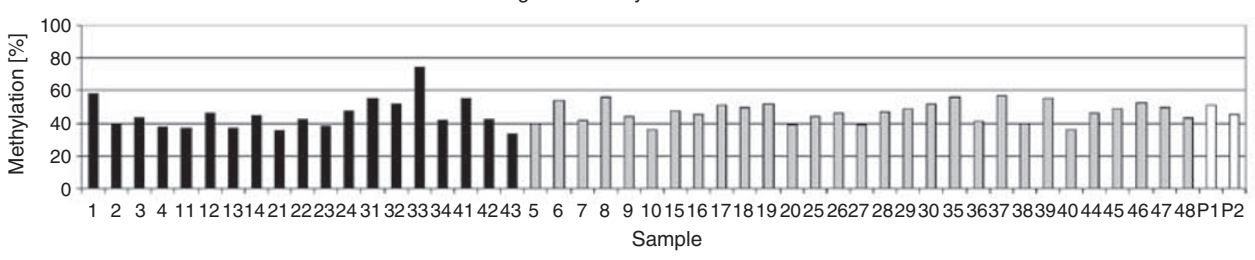

Degree of methylation at PEG1

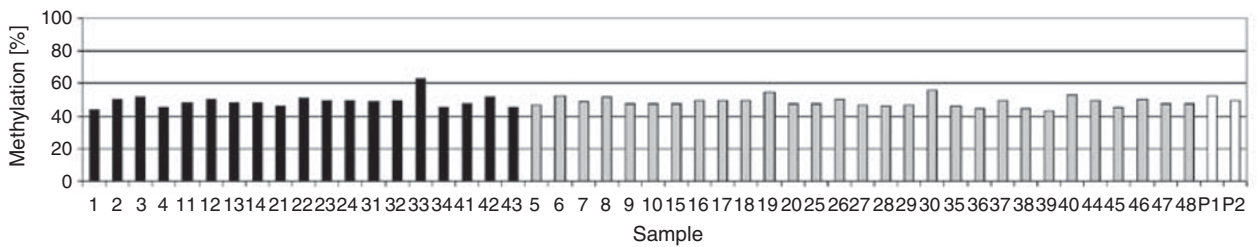

Degree of methylation at PEG3

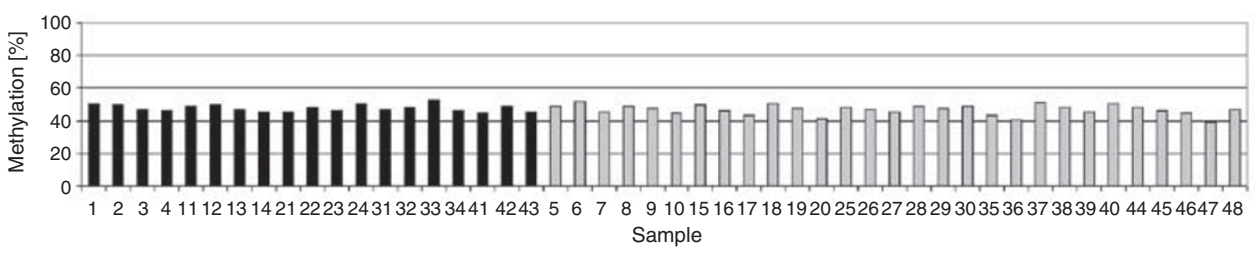

Degree of methylation at PLAGL1

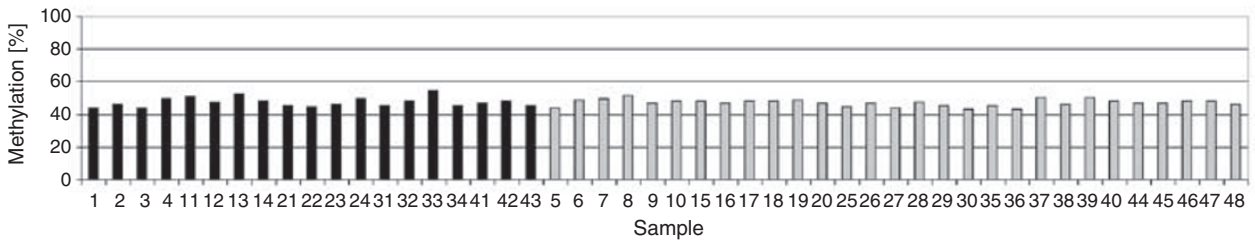

Degree of methylation at GTL2

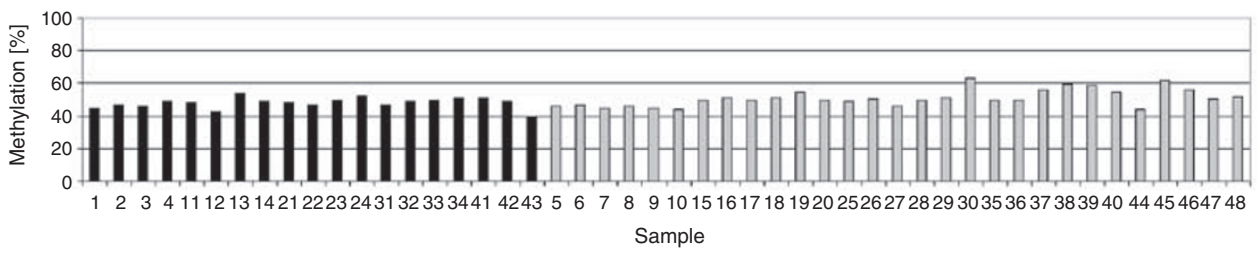

Degree of methylation at IGF2/H19

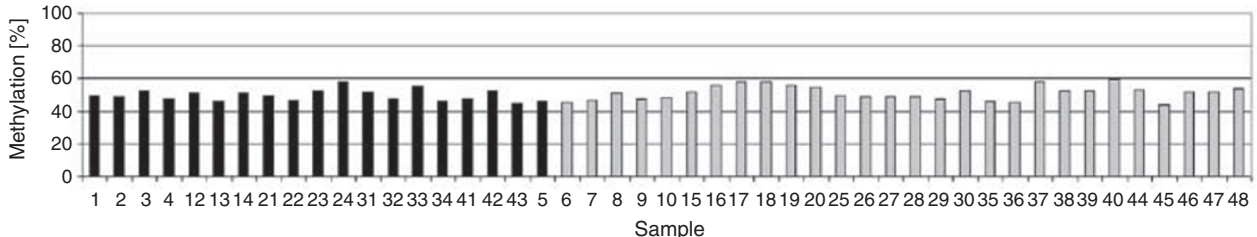

Figure 1 Methylation analysis by sequence-based quantitative methylation analysis (SeQMA). The histograms show the degree of methylation at six loci in intracytoplasmic sperm injection (ICSI)/small for gestational age (SGA) children (black bars), control children (gray bars) and the parents of child no. 33 (P1 and P2, white bars; KCNQ1OT1 and PEG1 only). Child no. 33 is hypermethylated at KCNQ1OT1 and possibly at PEG1. Her parents have normal methylation levels. Because of insufficient material of sample no. 11, we could not perform SeQMA for the locus IGF2/H19 for this sample.

heterozygous mice that inherited a mutant allele from the paternal germ line were smaller and lighter, but otherwise fertile.
CDKN1C is located in $11 \mathrm{p} 15$, encodes the cyclindependent kinase inhibitor p57KIP2 and is maternally expressed. Regulation of imprinted CDKN1C expression is 

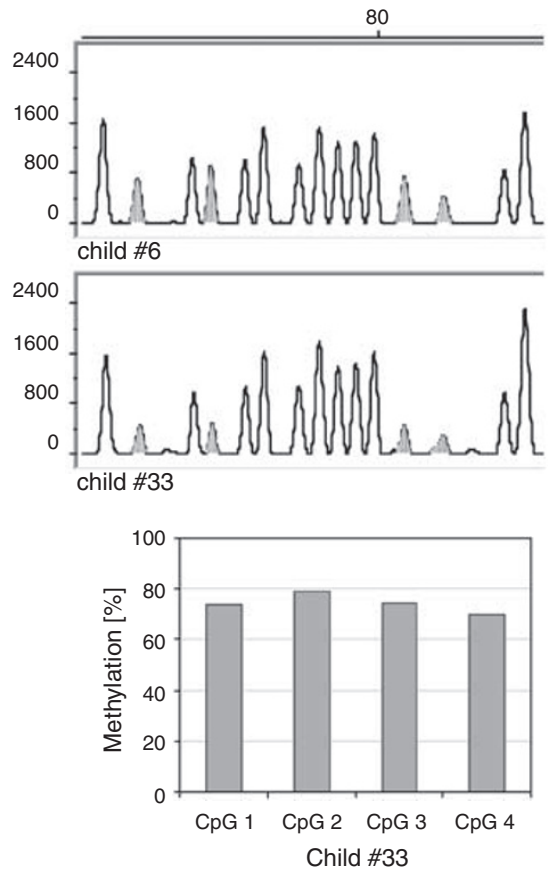

PEG1
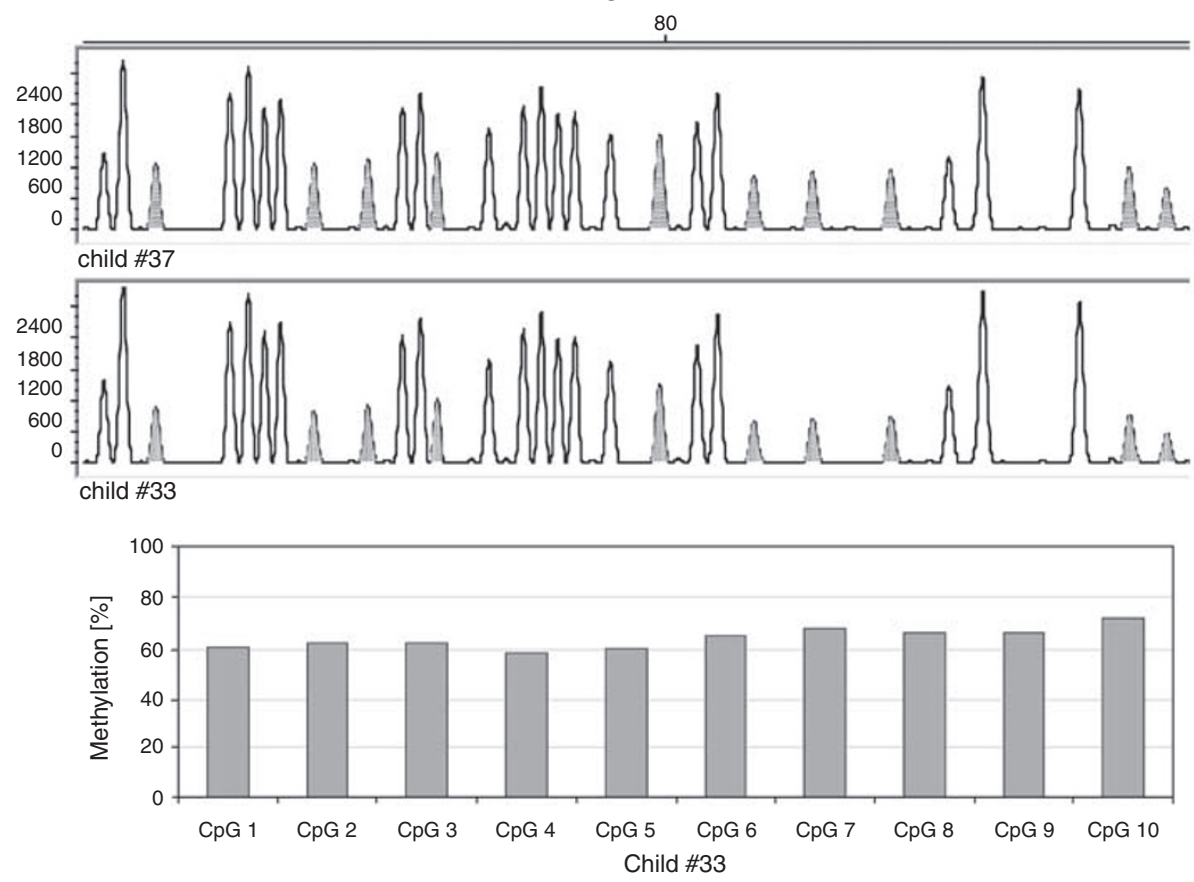

Figure 2 Single-site methylation analysis. Sequencing reactions were subjected to GeneScan analysis. The upper four panels show the T channel outputs for KCNQ1OT1 (left) and PEG1 (right). Thymine residues resulting from bisulfite conversion of CpGs to TpGs are indicated in gray. Compared to children of the control group, child no. 33 is hypermethylated at the KCNQ1OT1 CpGs and borderline hypermethylated at the PEG1 CpGs.

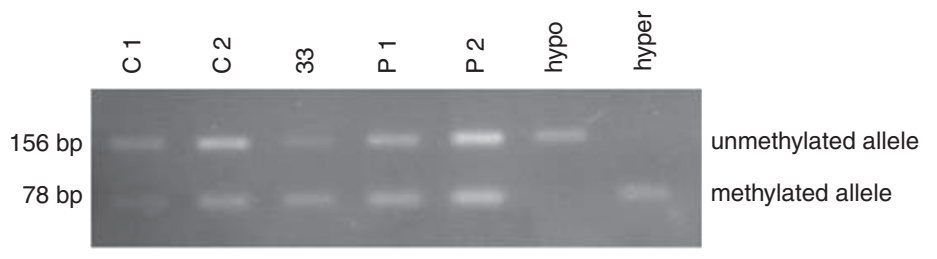

KCNQ1OT1

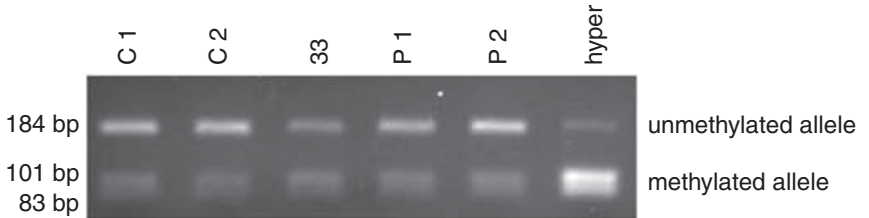

PEG1

Figure 3 Methylation analysis by combined bisulfite restriction analysis (COBRA). BstUl cleaves the bisulfite PCR products only, if the original DNA was methylated. In child no. 33, the relative intensity of the unmethylated KCNQ1OT1 and PEG1 bands is lower when compared to normal control (C1 and C2) and the parents (P1 and P2). Hypo, strongly hypomethylated control; hyper, strongly hypermethylated DNA sample. For PEG1, no hypomethylated DNA sample was available.

regulated by the maternally methylated KvDMR1 within intron 10 of the KCNQ1 gene, which also regulates expression of the paternally expressed KCNQ1OT1 transcript. ${ }^{17}$ Loss of $C D K N 1 C$ expression is associated with overgrowth (Beckwith-Wiedemann syndrome ${ }^{5}$ ). Maternal duplication of $11 \mathrm{p} 15$ is associated with growth retarda- tion, ${ }^{18,19}$ although this effect could also involve the IGF2/H19 cluster. Up to now hypermethylation of the KCNQ1OT1 locus has not been reported in humans, but probably leads to overexpression of $C D K N 1 C$ and thus may cause fetal growth retardation. A study of Fitzpatrick et $a l^{20}$ demonstrated that a paternal inheritance of a deletion 
of Kvdmr1 results in overexpression of six maternally expressed genes, including $C d k n 1 c$. The main feature of these knockout mice is growth retardation.

In summary, we note that the methylation changes of KCNQ1OT1 and PEG1 in child no. 33 are in the expected direction.

Assuming the methylation changes are authentic, what might be the cause? In general, epimutations after assisted reproduction may be linked to the fertility problems of the parents (father or mother) or the procedure. On the basis of studies in patients with Angelman syndrome, ${ }^{21,22}$ Beckwith-Wiedemann syndrome ${ }^{23-26}$ and animal models, ${ }^{6}$ it has been suggested that superovulation ${ }^{13,27}$ or cell culture ${ }^{23,24}$ might affect methylation at certain imprinted loci. These procedures are unlikely to be the reason for the abnormal methylation pattern in child no. 33. In the aforementioned studies, loss of methylation at maternal alleles at the SNRPN and KCNQ1OT1 loci had been found. In child no. 33, we have found hypermethylation of the paternal allele of KCNQ1OT1 and possibly PEG1.

A study of Kobayashi et $a l^{28}$ revealed that sperm from infertile men carry a higher risk of transmitting incorrect primary imprints to their offspring. Moreover, they found out that errors were more frequent at maternally methylated DMRs in the ejaculated sperm than at paternally methylated DMRs. Aberrant methylation of several maternally methylated loci such as PEG1, KCNQ1OT1, PLAGL1, $P E G 3$ and SNRPN in the ejaculated sperm are probably the result of errors in imprint erasure. Transmission of the aberrant imprint might thus be promoted during male infertility treatment. ${ }^{28-30}$ Therefore, it is likely that a sperm of the affected child's father, who had oligozoospermia, carried an incorrect imprint (hypermethylation at KCNQ1OT1 and PEG1), which was transmitted to the child.

Interestingly, Kagami et $a l^{31}$ found partial hypermethylation of PEG1 in a patient with Silver-Russell syndrome conceived after in vitro fertilization. Furthermore, four of the eight abnormally methylated cytosines were also methylated in the father. It was inferred, therefore, that the paternal PEG1 allele with mildly hypermethylated DMR was further methylated and transmitted to the patient.

If child no. 33 was conceived from a sperm carrying methylated KCNQ1OT1 and PEG1 alleles, why does she not have $100 \%$ methylation at these loci? Partial hypermethylation of these loci in child no. 33 reflects a mosaic situation, that is, the presence of hypermethylated cells and normal cells. Mosaic hypermethylation may result (i) from the postzygotic gain of methylation at these loci, possibly as a failure of a cell to protect the unmethylated paternal alleles against de novo methylation or (ii) from the postzygotic loss of an aberrant methylation imprint. It is difficult to link these defects to the assisted reproduction technology procedure.
On the basis of the methylation changes found in sperm of infertile men, including the PEG1 locus, it is tempting to speculate that the methylation changes in child no. 33 are linked to the fertility problem of the father. The following scenario would be compatible with the published data and our findings. Child no. 33 was conceived from a sperm that was abnormally methylated at KCNQ1OT1 and PEG1, probably as a result from a failure to erase the maternal methylation imprint during spermatogenesis. It has been shown in patients with Prader-Willi syndrome and a sporadic imprinting defect, that the chromosome carrying the imprint defect is always inherited from the paternal grandmother, ${ }^{32}$ strongly suggesting that defects in imprint erasure do occur. In contrast to a real maternal methylation imprint, the aberrant methylation pattern may not include each CpG within the DMR. As a consequence, this abnormal imprint may be less stable during postzygotic development, leading to complete loss in some cells. As such cells would have a proliferative advantage relative to a cell with KCNQ1OT1 and PEG1 hypermethylation, this cell line would outgrow the affected cell line. This scenario is speculative, but would explain the catch-up growth in this child.

In summary, imprinting defects appear to be a rare finding in ICSI children born SGA, at least at the loci investigated in this study. To the best of our knowledge, hypermethylation of KCNQ1OT1 has never been observed before in a normal or a growth-retarded child. It may represent a rare stochastic event or be linked to paternal subfertility, but not to in vitro fertilization/ICSI. Given the rare frequency of imprinting defects and the instability of defective imprints at certain loci, it will be necessary to collect newborn and placental tissue and to examine more children.

\section{Acknowledgements}

We thank Stefan Böhringer for helpful discussion and Stephanie Gro $\beta$ for expert technical assistance. This study was supported by the Deutsche Forschungsgemeinschaft.

\section{References}

1 Sutcliffe AG, Ludwig M: Outcome of assisted reproduction. Lancet 2007; 370: 351-359.

2 Horsthemke B, Ludwig M: Assisted reproduction: the epigenetic perspective. Hum Reprod Update 2005; 11: 473-482.

3 Miozzo M, Simoni G: The role of imprinted genes in fetal growth. Biol Neonate 2002; 81: 217-228.

4 Constancia M, Kelsey G, Reik W: Resourceful imprinting. Nature 2004; 432: 53-57.

5 Diaz-Meyer N, Day CD, Khatod K et al: Silencing of CDKN1C (p57KIP2) is associated with hypomethylation at KvDMR1 in Beckwith-Wiedemann syndrome. J Med Genet 2003; 40: 797-801.

6 Young LE, Fernandes K, McEvoy TG et al: Epigenetic change in IGF2R is associated with fetal overgrowth after sheep embryo culture. Nat Genet 2001; 27: 153-154. 
7 Reik W, Brown KW, Schneid H, Le Bouc Y, Bickmore W, Maher ER: Imprinting mutations in the Beckwith-Wiedemann syndrome suggested by altered imprinting pattern in the IGF2-H19 domain. Hum Mol Genet 1995; 4: 2379-2385.

8 Gicquel C, Rossignol S, Cabrol S et al: Epimutation of the telomeric imprinting center region on chromosome $11 \mathrm{p} 15$ in Silver-Russell syndrome. Nat Genet 2005; 37: 1003-1007.

9 Zeschnigk M, Albrecht B, Buiting K et al: IGF2/H19 hypomethylation in Silver-Russell syndrome and isolated hemihypoplasia. Eur J Hum Genet 2008; 16: 328-334.

10 Horsthemke B: Epimutations in human disease. Curr Top Microbiol Immunol 2006; 310: 45-59.

11 Katalinic A, Rosch C, Ludwig M: Pregnancy course and outcome after intracytoplasmic sperm injection: a controlled, prospective cohort study. Fertil Steril 2004; 81: 1604-1616.

12 Dikow N, Nygren AO, Schouten JP et al: Quantification of the methylation status of the PWS/AS imprinted region: comparison of two approaches based on bisulfite sequencing and methylation-sensitive MLPA. Mol Cell Probes 2007; 21: 208-215.

13 Sato A, Otsu E, Negishi H, Utsunomiya T, Arima T: Aberrant DNA methylation of imprinted loci in superovulated oocytes. Hum Reprod 2007; 22: 26-35.

14 Valleley EM, Cordery SF, Bonthron DT: Tissue-specific imprinting of the ZAC/PLAGL1 tumour suppressor gene results from variable utilization of monoallelic and biallelic promoters. Hum Mol Genet 2007; 16: 972-981.

15 Moore MW, Dietz LG, Tirtorahardjo B, Cotter PD: A multiplex methylation PCR assay for identification of uniparental disomy of chromosome 7. Hum Mutat 2003; 21: 645-648.

16 Lefebvre L, Viville S, Barton SC, Ishino F, Keverne EB, Surani MA: Abnormal maternal behaviour and growth retardation associated with loss of the imprinted gene Mest. Nat Genet 1998; 20: $163-169$.

17 Mitsuya K, Meguro M, Lee MP et al: LIT1, an imprinted antisense RNA in the human KvLQT1 locus identified by screening for differentially expressed transcripts using monochromosomal hybrids. Hum Mol Genet 1999; 8: 1209-1217.

18 Fisher AM, Thomas NS, Cockwell A et al: Duplications of chromosome $11 \mathrm{p} 15$ of maternal origin result in a phenotype that includes growth retardation. Hum Genet 2002; 111: 290-296.

19 Schonherr N, Meyer E, Roos A, Schmidt A, Wollmann HA, Eggermann T: The centromeric $11 \mathrm{p} 15$ imprinting centre is also involved in Silver-Russell syndrome. J Med Genet 2007; 44: $59-63$.
20 Fitzpatrick GV, Soloway PD, Higgins MJ: Regional loss of imprinting and growth deficiency in mice with a targeted deletion of KvDMR1. Nat Genet 2002; 32: 426-431.

21 Cox GF, Burger J, Lip V et al: Intracytoplasmic sperm injection may increase the risk of imprinting defects. Am J Hum Genet 2002; 71: $162-164$.

22 Orstavik KH, Eiklid K, van der Hagen CB et al: Another case of imprinting defect in a girl with Angelman syndrome who was conceived by intracytoplasmic semen injection. Am J Hum Genet 2003; 72: 218-219.

23 Maher ER, Brueton LA, Bowdin SC et al: Beckwith-Wiedemann syndrome and assisted reproduction technology (ART). J Med Genet 2003; 40: 62-64.

24 DeBaun MR, Niemitz EL, Feinberg AP: Association of in vitro fertilization with Beckwith-Wiedemann syndrome and epigenetic alterations of LIT1 and H19. Am J Hum Genet 2003; 72: $156-160$.

25 Gicquel C, Gaston V, Mandelbaum J, Siffroi JP, Flahault A, Le Bouc Y: In vitro fertilization may increase the risk of BeckwithWiedemann syndrome related to the abnormal imprinting of the KCN1OT gene. Am J Hum Genet 2003; 72: 1338-1341.

26 Halliday J, Oke K, Breheny S, Algar E, J Amor D: BeckwithWiedemann syndrome and IVF: a case-control study. Am J Hum Genet 2004; 75: 526-528.

27 Ludwig M, Katalinic A, Gross S, Sutcliffe A, Varon R, Horsthemke B: Increased prevalence of imprinting defects in patients with Angelman syndrome born to subfertile couples. J Med Genet 2005; 42: 289-291.

28 Kobayashi H, Sato A, Otsu E et al: Aberrant DNA methylation of imprinted loci in sperm from oligospermic patients. Hum Mol Genet 2007; 16: 2542-2551.

29 Marques CJ, Carvalho F, Sousa M, Barros A: Genomic imprinting in disruptive spermatogenesis. Lancet 2004; 363: 1700-1702.

30 Marques CJ, Costa P, Vaz B et al: Abnormal methylation of imprinted genes in human sperm is associated with oligozoospermia. Mol Hum Reprod 2008; 14: 67-74.

31 Kagami M, Nagai $T$, Fukami M, Yamazawa $\mathrm{K}$, Ogata $\mathrm{T}$ : Silver-Russell syndrome in a girl born after in vitro fertilization: partial hypermethylation at the differentially methylated region of PEG1/MEST. J Assist Reprod Genet 2007; 24: 131-136.

32 Buiting K, Gross S, Lich C, Gillessen-Kaesbach G, el-Maarri O, Horsthemke B: Epimutations in Prader-Willi and Angelman syndromes: a molecular study of 136 patients with an imprinting defect. Am J Hum Genet 2003; 72: 571-577.

Supplementary Information accompanies the paper on European Journal of Human Genetics website (http://www.nature.com/ejhg) 